\title{
CONCEPTUAL SCHEMAS AS PROPOSITIONAL IDEALIZED COGNITIVE MODELS: IN SEARCH OF A UNIFIED FRAMEWORK FOR THE ANALYSIS OF KNOWLEDGE ORGANIZATION1
}

\author{
Francisco José Ruiz de Mendoza Ibáñez \\ Cristina Pascual Aransaez \\ Universidad de La Rioja
}

\begin{abstract}
RESUMEN: En este artículo se trata la cuestión de la organización del conocimiento proposicional en forma de redes conceptuales. A este respecto, seguimos las ideas expuestas en Ruiz de Mendoza (1996), intentando hacerlas compatibles con las propuestas, todavía programáticas, de autores cognitivistas como Langacker y Lakoff. Señalamos algunas de las deficiencias de sus trabajos y argumentamos a favor de una explicación unificada según la cual las caracterizaciones semánticas adoptan la forma de redes conceptuales que -una vez activadas- producen conjuntos de proposiciones ordenadas según su grado de prominencia. Para ilustrar nuestra tesis, desarrollamos diversos aspectos del esquema conceptual relativo a la palabra party.
\end{abstract}

ABSTRACT: This paper addresses the issue of the organization of (propositional) knowledge in the form of conceptual networks. We follow closely Ruiz de Mendoza's (1996) proposal in this respect and we try to make it compatible with the still programmatic proposals made in Cognitive Linguistics by Langacker and Lakoff. We discuss some of the main deficiencies in each account and provide arguments for the possibility of a unified account where semantic characterizations take the form of conceptual networks whichwhen activated-produce sets of propositions arranged according to degrees of prominence. We illustrate our arguments by discussing the conceptual schema for party.

\section{Introduction}

In recent years defenders of the encylopedic conception of semantics have made a number of proposals for its treatment within linguistic theory. Thus, Fillmore (1985) has proposed the notion of 'interpretive frame' as structuring what he calls a ' $U$ -

1. Financial support for this research has been provided by the DGES, grant no. PB96-0520 and by the University of la Rioja, grant no. API-97/B18. 
semantics" or semantics of understanding as opposed to a 'T-semantics' or semantics of truth. Lakoff (1987), who abides by the notion of 'interpretive frame', has proposed that frames are only one type of knowledge construct or 'idealized cognitive model' (ICM) to take into account. More specifically frames are propositional ICMs, while metaphor, metonymy, and Johnson's (1987) image-schemas are other forms of ICM which have linguistic relevance and should have a place in semantic description. Langacker (1987), on the other hand, has taken a different stance by arguing that semantic characterizations should be sensitive to the criteria of centrality and network organization.

Lakoff's and Langacker's proposals have in common their rejection of the truthconditional, objectivistic approach to meaning and their acceptance of the encyclopedic view of semantics. However, they differ substantially in scope and in detail. As a result, cognitive linguistics still lacks a unified framework for the analysis of knowledge organization. In what follows, we shall try to provide the groundwork for such a framework to be possible. In order to do so, we shall take advantage of and develop some of the proposals made by Ruiz de Mendoza $(1995,1996)$ with respect to the nature of semantic networks. Ruiz de Mendoza's work in this connection is in turn a developement of the basic insights provided by Langacker (1987). However, as will become evident below, his account must be improved in several respects, which we shall do in the light of some of Lakoff's observations on the nature of propositional models ${ }^{2}$. We shall proceed in three stages. First, we shall argue for the possibility of making compatible some aspects of prototype theory and of the classical theory of categorization. Second, we shall study Langacker's criteria of centrality and network organization. This will lead to a third stage where Lakoff's proposal will be revised and a new approach will be offered.

\section{Conditions for category membership}

As Taylor (1989: 38) has observed, prototype theory has seriously challenged the foundations of the classical, Aristotelian theory of categorization. According to the classical view, categories are homogeneous unities with clear-cut boundaries and two degrees of membership, namely, member and non-member. Membership in a category is defined in terms of a fixed set of necessary and sufficient conditions which have

2. Fillmore's analysis, as evidenced for example by the work in Fillmore \& Atkins (1994), goes one step further than Lakoff's observations on propositional ICMs since he takes systematically into account the relationship between frame internal elements and their grammatical realizations. However, we feel that an analysis of grammatical realizations has to be postponed until it is clear what the semantic potential of frame constituents is. Moreover, since extant proposals do not seem to have provided a framework of analysis which allows to systematize regularities across different frames (or cognitive models), we attempt to provide such a framework herein. 
equal status and complex concepts can be reduced to sets of binary primitives ${ }^{3}$. As a result, in the classical view, things either belong or do not belong to a category. Prototype theory, on the other hand, has shown empirically that the classical view is not psychologically real: categories are not homogeneous and their boundaries are fuzzy. Moreover, there are degrees of membership in a category. In fact, category membership is determined by similarity to the what has been called the prototype or best example of the category ${ }^{4}$. Categories are defined in terms of attributes, which are not all-or-nothing properties of things but rather dimensions along which different entities are regarded as similar. So, membership in a category is ultimately determined on the basis of these attributes. However, this hypothesis of categorization leaves a fundamental problem unresolved: even though they have fuzzy boundaries, categories cannot be unrestricted. If unrestricted, a category would encompass the whole universe of entities, since it is possible to establish some kind of similarity between virtually any pair of objects. So, there must be some constraint which guarantees category boundaries.

A solution to this problem may be found in recognizing the existence of essential attributes (not necessary and sufficient conditions) for categories. This proposal leaves the door open for encyclopedic semantics in that it does not restrict the number of elements that may ultimately become part of a semantic characterization under certain conditions, but at the same time it makes categories manageable by placing some limitations on them. The proposal does not involve that membership in a category is a matter of all or nothing and does not impose rigid boundaries on categories, either (i.e. categories are still fuzzy). However, it guarantees at least one form of category boundary. In the next section we discuss how this integrated model may become possible.

\section{A network conception of encyclopedic knowledge}

Langacker $(1987,1990)$ has argued that the problems of the open-endedness and the accessibility of encyclopedic knowledge may be satisfactorily solved in terms of centrality and network organization. He claims that not all the facets of our knowledge have equal status, and that some specifications that figure in our encyclopedic

3. Langacker has questioned this assumption contending that especially when dealing with basic level categories, cognitive structures are usually understood as holistic, gestalt configurations more than as attribute bundles. That is, the parts are understood in terms of the whole, rather than vice versa. See Langacker (1987: 19ff).

4. Rosch (1978), who was the developer of the Theory of Prototypes, abandoned her view that prototypes constituted a theory of representation for categories and made clear that what her experimental findings simply proved was that categories show prototype effects. Prototype effects are by-products of categorization. 
conception on an entity are central and others are peripheral. In his view, centrality correlates with the extent to which a specification is (i) conventional (i.e. shared by a community of speakers, which makes it linguistically significant), (ii) generic (it will be more easily known in a speech community than a specific category), (iii) intrinsic (i.e. it makes no essential reference to external entities), and (iv) characteristic (i.e. it is sufficient to identify a member of a class of entities).

Langacker also believes that expressions should not be considered to be containers for meaning. Instead, attention must be focused on the symbolic correspondence between phonological and semantic features. He understands concepts as entrenched cognitive routines which are interrelated in such a way that they may be coactivated if necessary (see Langacker, 1987: 162). This conception is further articulated in terms of a network model, in which each entity designated by a symbolic unit becomes a "point of access" to a network and its semantic value is seen as the open-ended set of relations in which the "access node" participates. This can be used, for example, to explain how we establish a link between cat and cheese without saying that the concept of 'cheese' figures directly in that of 'cat': we ascribe to cats the property of chasing mice and to mice that of eating cheese 5 .

As noted in Ruiz de Mendoza (1996), Langacker does not describe what a relational network is like, nor the number and kind of relations that it should have. To these problems we may add that Langacker has not accounted for how relational networks determine prototype effects. In an attempt to flesh out Langacker's proposals and solve theoretical problemas like the ones mentioned, Ruiz de Mendoza (1996) has proposed that concepts take the form of "conceptual schemas". These consist of a "general definer" -which is the set of necessary attributes which provide the blueprint for the identification of a concept as such- plus a number of related prototypical associations which are instantiated by means of a set of (predictable) "relational arcs". In the following section, we shall take advantage of Ruiz de Mendoza's development of Langacker's assumptions (that is, the need of considering the criteria of centrality and network knowledge structure) and we shall suggest how they can be used to improve the notion of Lakoff's propositional 'idealized cognitive models' (or ICMs).

This is the set of relational arcs proposed by Ruiz de Mendoza (1996: 348-351)6:

Internal relations:

Action types: Agentive (does/ is done by), factitive (makes/is made by), purposive (is used for/ is performed by means of), causative (causes/is caused by), resultative (produces/ is produced by);

5. Fauconnier's theory of mental spaces is compatible with Langacker's proposal, because the former postulates the existence of small conceptual packets which are constructed provisionally by people when needed for the cognitive activity in which they are engaged (Fauconnier, 1994).

6. See Ruiz de Mendoza $(1995,1996)$ for a more detailed discussion on relational arcs. 
Process types: Processual (does/ is done by), originatory (originates/ is converted into);

Position type: Positioner (has/ is had by);

State types: Material (is made of/is the material of), container (contains/is containes by), partitive (is a part of/ consists of), locative (is found in), attributive (is a property of/ is a quantity of).

\section{External relations:}

Paradigmatic: Classifying (is a type of/is classified into);

Syntagmatic: Identifying (is/is like), contrasting (is in contrast to), opposing (is the opposite of), analogising (is analogous to).

The application of a subset of these relations to a concept yields a set of propositions which constitute the conceptual schema for the concept. Consider the concept of 'table'. The application of the material relation produces a proposition like 'a table is typically made of wood'; the purposive relation produces a proposition like 'a table is typically used for putting things on', and so on. Or think of the concept of 'hunter': a hunter typically hunts wild animals (agentive relation) for sport (purposive relation). Note that both concepts activate the purposive relation, but 'table' does not activate the agentive relation and 'hunter' does not make use of the material relation.

From our point of view, several benefits may be derived from this proposal. First, it makes it possible to look for regularities in the internal make-up of concepts in such a way that the propositions derived may be listed in an orderly way and comparisons between concepts may be rigorously made. Second, it safeguards the centrality criterion, since concepts are included in the schema in successive layers of activation. Third, it is sensitive to the requirements of prototype theory since the propositions focus on the attributes which provide the best example of the category which they contribute to define. Fourth, postulating the existence of necessary attributes (or definers) facilitates contrast between concepts which share some attributes (e.g. synonyms, antonyms, hyponyms, etc.). However, Ruiz de Mendoza (1996) has not taken into account the possibility of grouping the sets of propositions which make a up a conceptual schema in the form of cognitive models with a holistic structure. For this reason, his proposal is -in its present state of formulation- incapable of dealing with non-central extensions of concepts in a way which accounts for why some extensions make use of some portions of the internal make-up of concepts to the exclusion of others. This deficiency is related to the question of the degrees of prominence of some models with respect to others, an issue which shall be addressed below. 


\section{Conceptual schemas as propositional ICMs}

Ruiz de Mendoza (1996) has not considered the connections between his proposal and Lakoff's notion of propositional ICMs. However, it will be seen that the two accounts are largely complementary with only some minor modifications. To begin with, an ICM is a conventionalized pattern of belief or communication used in understanding. For Lakoff, concepts are non-primitive "gestalt-structures" based on bodily or social experience. Lakoff's proposal is grounded in empirical findings in cognitive psychology on prototype effects (see Rosch, 1978). According to him, we organize knowledge in the form of ICMs; prototype effects (i.e. scalar goodness-ofexample ratings for categories), on the other hand, show nothing about the nature of categorization, but are the by-product of the use of ICMs. Each ICM makes use of one of four kinds of structuring principle: propositional, image-schematic, metaphoric, and metonymic, and the activity of each of them is a source of prototype effects.

We shall focus on the description of propositional models, since at least metaphoric and metonymic models are extensions of them. Note in this connection that image-schemas are spatial constructs which are not related to propositional models (see Johnson, 1987).

Lakoff (1987:74ff) analyses the concept of 'mother' as an example of what he calls a "cluster model": a combination of cognitive models which form a complex cluster that is psychologically more basic than the models taken individually. The models in this cluster are the 'birth' model (cf. the expresssions surrogate mother, biological mother), the 'genetic' model (cf. donor mother), the 'nurturance' model (cf. adoptive mother, foster mother), the 'marital' model (cf. stepmother) and the 'genealogical' mother (according to which the closest female ancestor is the mother).

All these models taken together form a cluster of converging cognitive models, and the cluster is a central subcategory. The rest are divergences from this cluster and are considered to be variants of it or noncentral extensions (adoptive mother, stepmother, etc.). There is an ideal model, which is the central case where the models in the cluster converge. This ideal model includes: "a mother who is and always has been a female, and who gave birth to a child, supplied her half of the child's genes, nurtured the child, is married to the father, is one generation older than the child, and is the child legal's guardian" (Lakoff, 1987:83). This leads Lakoff to conclude that the category of mother has a "radial" structure formed by a central subcategory and noncentral extensions. These variants are extended by convention and must be learned. They are determined by the central model and cannot be predicted by general rules. Furthermore, they are not understood completely in their own terms, and have to be comprehended via their relationship to the central concept of 'mother'. That is, the radial structure within a category is a source of prototype effects. 
Though interesting, there are some inconsistencies in Lakoff's account, which can be overriden if we propose some modifications in the basic conception of propositional ICMs. First, let us discuss Lakoff's notion of centrality.

Lakoff's proposal does not lack the idea of centrality, which is a key characteristic of semantic specifications. However, it is not the idea of centrality itself but the way he understands it within his propositional ICMs that may be found problematic. Here we shall take sides with Ruiz de Mendoza (1996) and argue in favour of a notion of centrality in which there are some conditions which are essential for the definition of a concept, while others are peripheral. That is, we do not think that centrality is a matter of models but of necessary (though not sufficient) conditions (what Ruiz de Mendoza has called the general "definers" of concepts). This must not be taken to be a claim in favour of the classical theory of categorization, so this does not preclude postulating the existence of prototype effects as a result of the use of concepts, which could be an objection raised by those in favour of Lakoff's model. Following Ruiz de Mendoza (1996), the structure of the category 'mother' is that of a conceptual schema whose general definer is 'woman who has (had) (at least) a child', and which can be instantiated in different ways ${ }^{7}$. The different forms of instantiation produce a range of prototype effects.

In order to illustrate this view, let us take the concept of 'party'. In general, dictionaries do not provide evidence for Lakoff's assumption of an 'ideal case'. Consider8:

- Collins Cobuild Dictionary: "a social event, often in someone's home, at which a number of adults or children enjoy themselves by eating, drinking, dancing, talking, playing games, etc.".

- Chambers 20 C Dictionary: "a small body of persons associated together in any occupation or amusement. A meeting or entertainment of guests".

- Oxford Advanced Learner's Dictionary: "a social gathering to which people are invited, especially in order to celebrate something".

- Longman Lexicon of Contemporary English: "(the activities, entertainment, etc.) of a group of people who have been invited to a house, hotel, etc. for some kind of entertainment" /"a gathering of people, by invitation for amusement".

- Webster's Third New International Dictionary: "a social gathering. Also: the entertainment provided for it".

However, they do reflect our three general definers for the concept of 'party'.

7. See Ruiz de Mendoza (1996) for a more detailed analysis in terms of conceptual schemas and prototypical associations.

8. We have been aware of the effect that the British vs. the American language variety might have on the data, and have been careful to compare like with like. 
These definitions are good illustration of the prominence of two ideas: (i) a party is defined as a social event, and (ii) people attend a party to enjoy themselves. A third -not so prominent- piece of information is that people are invited to parties. Now, if we make use of Ruiz de Mendoza's proposal, 'party' can be analysed as a set of necessary conditions (understood as essential attributes which can be expressed propositionally), plus their related prototypical associations which form its prototypical core. Thus, 'party' invokes a schema with a set of general definers, namely: 'merry-making', 'social gathering', and 'people are invited'. Each of these definers may be variously instantiated. For instance, for the merry-making definer one may come up with such prototypical possibilities as dancing, singing, drinking, people performing tricks or telling jokes. Other instantiations such as 'musicians playing opera highlights' may have a merry-making connection with the party schema, but they are part of its periphery (this instantiation would rather belong to the 'eighteenth century party' schema). So, despite possible variations, the definers remain the same. Consider the following utterances:

(1) I met a lot of friends at the party.

(2) ? I went to the party because I wanted to be alone.

(3) I will ask John to come to my party.

(4) ? I will not invite anybody to the party because I hope people will come.

(5) If Tom tells some of his jokes at the party everybody will have a good time.

(6) ? I went to the party to translate Crime and Punishment into English.

In each of the examples above, a definer is exploited explicitly while the others remain implicit. However, all of them have to be present either implicitly or explicitly in all sentences for us to understand the concept of party. (1) is semantically plausible (or consistent) because one of the definers of 'party' is that it is a 'social gathering'. By the same token, (2) is inconsistent because if there is only a person there cannot be a party, except perhaps in the case that a person acted out different roles pretending to be other people, which is clearly not the case here. (3) is semantically plausible because one of the definers for 'party' is 'people are invited'. Here the speaker is the host and he invites another person to his party. (4) is semantically implausible because we know that people are not expected to go to a party if they are not invited. Even if there were a party with no host -which is not usual- and participants were self-invited, they would belong to the party as long as they were accepted by others. (5) is semantically plausible because it calls up the idea of merry-making, which is another definer. Finally, (6) is semantically implausible because parties are held for people to have fun and translating a book would be odd as a merry-making activity.

Notice that this is different from what Lakoff seems to suggest for propositional ICMs which are based on the convergence of models which have the same status. We do not reject Lakoff's proposal, but we redefine it. First, the set of general definers for 'party' does not characterise an 'ideal case' -as with Lakoff's propositional ICMs- but 
is always present in any kind of party. As a matter of fact, these general definers are constitutive for the concept. Thus, we can substitute any subcategory of party (school party, birthday party, etc.) for the term party above and examples (1), (3), (5) will remain semantically plausible. Thus, the notion of conceptual schema allows us to understand any subcategory without having to refer to an ideal case. Moreover, by providing a common core of conditions, it shows clearly that subcategories are related to one another.

Second, we disagree with Lakoff's view that all the models in a cluster have the same importance. Thus, Lakoff argues -in relation to his discussion of 'mother'- that although there is always a "strong pull" to view one model as the most important which is thought by some to be what characterizes the "real" concept of mother- the linguistic evidence does not bear this out (Lakoff, 1987:75). However, we think that people's tendency to pick one model (or two) as being the ones that "really" define a mother is reflected in our language. We do not mean that linguistic evidence shows that only one of these models characterizes the concept of 'mother' completely, but it makes it clear that not all of them characterize it in the same way; there are degrees of prominence which are related to cultural expectations, and linguistic evidence does bear this out. This is something which Lakoff does not seem to take into account. He claims that even dictionary-makers show that there is no generally accepted cognitive model for 'mother' and illustrates his view (Lakoff, 1987: 75-76). However, what he shows is that most dictionaries list as the primary meaning of mother the 'birth' or 'nurturance' models, and in our opinion this is meaningful. The prominence of these two models should be taken into consideration because it is constantly present in language, as we shall see.

Lakoff provides the following examples to demonstrate that linguistic evidence does not provide any criterion for "real" motherhood (the emphasis is ours):

(7) I was adopted and I don't know who my real mother is.

(8) I am not a nurturant person, so I don't think I could ever be a real mother to any child.

(9) I had a genetic mother who contributed the egg that was planted in the womb of my real mother, who gave birth and raised me.

(10) By genetic engineering, the genes in the egg my father's sperm fertilized were spliced together from genes in the eggs of twenty different women. I wouldn't call any of them my real mother. My real mother is the woman who bore and raised me, even though I don't have any single genetic mother.

Paradoxically, the examples Lakoff uses confirm our claim that linguistic evidence shows that some models -the 'birth model' (7),(9),(10) and the 'nurturance model' (8), (9), (10)- are more prominent than the others in order to understand the concept of 'mother', and that they are used by people as criterial to 'real motherhood' (although this does not mean that the rest must be ignored). 
Compound expressions and different extended senses of 'mother' also prove that, contrary to Lakoff's assumptions (1987:76), there are some privileged models for 'mother' on which these extensions are based. For example, the 'birth model' is the basis of the metaphorical sense in the sentence Necessity is the mother of invention, or in the terms motherland and mother-to-be. The nurturance model is the basis of the metaphorical sense in expressions like mother tongue, mothership, motherland (again), and mother-figure. Even though there are some metaphorical extensions which are based on other models (for instance, the use of the concepts 'mother' and 'daughter' to explain syntactic relationships, based on the genealogical model), these are fewer in number.

The same can be said of the concept of party where the 'merry-making' definer seems to be more prominent. There is linguistic evidence that substantiates this point. Consider the expression We have been partying all night, where to party is essentially 'to have a good time'. Or consider expressions like one's party piece (something often done to entertain people, especially at parties, for example singing a particular song or saying a particular poem), the party is over (used to indicate that the present situation, which is enjoyable, is going to change for worse), and the life and soul of the party (used to refer to somebody who by his high spirits, wit, social assurance, etc. enlivens a party). There are also some expressions which are based on other definers. For example, partycall, which is used for a call upon one's host or hostess after a party, is based on the 'people are invited' definer. However, the expressions based on the 'merry-making' definer prevail. Thus, we may conclude that the notion of 'prominence' is relevant in order to account for cultural expectations, and it is reflected in language.

It must be noted that the expressions mentioned above are used to foreground part of the internal make-up of the concept of party. In this sense, they have to do with Ruiz de Mendoza's description of 'internal relations'. Thus, if an agentive arc defines relations between participants, the life and soul of a party will be just one type of participant who has a number of characteristic properties (attributive relation). This suggests that Ruiz de Mendoza's classification of relation types may be used to produce sets of propositions which are sensitive to the requirements of a network configuration, as posited by Langacker. Other expressions are based on the external relations of the concept of party, more specifically on the classifying relation. These exploit any definer, not just the most prominent one, perhaps because here it is not the internal structure of the concept that is at issue. Consider the following cases:

-'Merry-making' definer:

Bottle party: Social event to which adults are invited to enjoy themselves. It takes place at someone's home ${ }^{9}$ and guests provide the drink.

9. Notice that location and time are more general defining parameters which are prototypically instantiated. It must be noted that in the cases in which we have not specified the reason for the party, it has been because there is not a special one. It is noteworthy that there is only one type of party which has been defined as 'formal social event' in contrast to the rest, which are informal most of the times. 
-'Social gathering' definer:

a) Focusing on where the gathering takes place:

School party: Social event to which schoolchildren are invited to enjoy themselves. It takes place in a school;

Garden party: Formal social event to which adults are invited to enjoy themselves. It takes place in a garden, usually in the afternoon.

b) Focusing on the type of people who attend the gathering:

Hen party: Social event to which only women are invited to enjoy themselves. It is held because a woman is going to get married. It takes place in a house or a hotel;

Stag party: Social event to which only men are invited to enjoy themselves. It is held because a man is going to get married. It takes place in a house or a hotel ;

Pyjama party: Social event to which only girls are invited in order to enjoy themselves. It takes place in a girl's house.

c) Focusing on the purpose of the social gathering:

Birthday party: Social event to which adults and/or children are invited to enjoy themselves. It is held because it is somebody's birthday. It takes place in a house or a hotel.

Welcome party: Social event to which adults and/or children are invited to enjoy themselves. It is held to receive a person. It takes place in a house or a hotel;

Farewell party: Social event to which adults and/or children are invited to enjoy themselves. It is held to take leave of a friend. It takes place in a house or a hotel.

Lakoff's proposal also misses one important aspect of knowledge organization by focusing exclusively on the internal structure of concepts. There are concepts which impose external constraints on the meaning of others. Let us consider the following, all of them externally relatable to 'party': 'celebration', 'ball', 'games'10, 'feast', and 'festival'. The concept of 'celebration' is the most generic one (in fact, it is an instantiation of the "classifying arc"); its general definers are based on the ideas of 'merry-making' and 'social gathering'. The other concepts are in a contrasting relation with 'party' and differ from 'celebration' in that they add new definers. Thus, 'party' adds the 'people are invited' definer; 'ball' adds the 'dancing' definer; 'games' includes two more general definers, namely, 'public entertainment' and 'activities to

10. Notice that we refer to "games", not "game". The latter is a merry-making activity and as such it may be present in some parties. 
compete'; 'feast' and 'festival' also add the 'public entertainment' definer, but they differ from 'games' and from each other: 'feast' includes 'religious celebration' as its general definer, whereas 'festival' adds these ones: 'celebrated at a special time of the year' and 'pagan (or Christian) connections'. It can be observed that there are important differences between this kind of analysis and the one carried out along structuralist lines -as we find in Leech (1981) or in Coseriu and Geckeler (1981). First, definers are not sets of both necessary and sufficient conditions, but only of necessary conditions; that is to say, our analysis admits the possibility of enriching the internal structure of concepts as much as needed for the purpose of semantic interpretation. Second, definers are the blueprint for the orderly activation of other concepts in interpretation (this is what we may call the "instantiation" of a definer). Our analysis additionally shows that the general definers of each of these concepts may be present in the others, but they are not essential for the understanding of them (i.e. each concept has its own general definers).

Conceptual schemas are basic-level categories and relational systems deal only with basic-level non-complex concepts. However, this does not mean that complex concepts such as 'party' cannot be analysed by means of relational networks. They can, provided that they enter a network as composites of non-complex categories. A 'party' is a complex concept which consists of the following meaning constituents: activities (kisses, handshakes, dancing, eating, drinking, etc.) and entities (host, guests, drinks, food, etc.). These elements provide the first level of instantiation of the general definers of 'party'. Consecutive levels of instantiation can be applied to these basic-level elements and they will provide increasingly peripheral associations with 'party'. As an illustration of our claim we propose the brief story below ${ }^{11}$ :

The guests arrived at the house. The host received them and there was a profusion of kisses and handshakes. In that special event there was music and dancing and people drank and ate a lot. When the party was over, the guests took leave of their host and went home.

As a social event a party consists of a number of activities (performed by a number of participants) that happen at a certain place and time (usually at a house and in the afternoon). Nevertheless, the locative and temporal instantiations are not necessarily performed by the language user for interpretation, either implicitly or explicitly. Note that here the former is performed as an explicit assumption ('at the house', locative arc). In a party a host invites people. This is essential for the coherent interpretation of the text, and helps us to understand why the guests arrived at the host's house. This is why it forms part of the set of general definers ('people are invited'). The host and the guests meet (agentive arcs). This is also necessary for the

11. For a similar analysis on the concept of 'trial', see Ruiz de Mendoza (1996: 353-54). 
coherent interpretation of the text, because it forms part of another general definer ('social gathering'). There are different forms of greetings: 'kisses', 'handshakes' (classifying arcs). 'Music', 'dancing', 'drinking' and 'eating' are kinds of merrymaking activities (classifying arcs). We assume that people had a good time, since this is the purpose (purposive arc) of the activities mentioned above and especially because this is essential for a general definer of 'party' ('merry-making'). There is an identifying relation between 'special event' and 'party' -which gives further cohesion to the text- and at the end the guests take leave of their host (agentive arc).

As we can observe, the text is based on explicit assumptions which are consistent with the prototypical conceptualizations provided by the relational arcs. It must be noted that the definers of the concept must be present either as explicit assumptions or as implicit assumptions for the interpreters of the text to understand that it is a 'party' that is being talked about.

\section{Conclusion}

This paper has revised Lakoff's analysis of propositional ICMs. Lakoff's proposal is appealing especially because of its purported empirical basis and it cannot be bluntly rejected. However, the aim of this paper has been to redefine it in order to attempt to sort out some of the problems it presents.

Lakoff's proposal lacks a system which regulates the convergence of the different models which make up a concept; it also ignores that some models are more prominent than others. We have suggested that these limitations can be sorted out if, following Ruiz de Mendoza (1995, 1996), we develop ICMs in terms of conceptual networks. A conceptual network consists of a set of general definers (Langacker's "access node") plus their related prototypical associations (the network). As a result of the activation of the relational network for a concept we obtain sets of propositions which are arranged according to degrees of centrality (this is a source of prototype effects). A set of propositions constitutes a propositional ICM.

There are two particularly prominent advantages in making Ruiz de Mendoza and Lakoff's proposals compatible. One, since a relational network is only partially activated when used, the principle of economy is observed. This makes the account all the more psychologically plausible and particularly sensitive to findings in Fauconnier's (1994) theory of "mental spaces". Two, once it is acknowledged that a conceptual schema has radial structure, it is possible to account for non-central extensions of it in relation to the particular definer which is exploited for the extension.

The network conception has another important advantage: Lakoff's proposal focuses on the internal structure of concepts, but our developement of Ruiz de 
Mendoza's approach can also be used in order to explain relations between concepts, inferential patterns and coherence phenomena.

For all the above reasons, it is our belief that the analysis of (propositional) conceptual structure in terms of semantic networks which structure ICMs can lead to a better understanding of the nature of knowledge organization.

\section{References}

COSERIU, E. \& GECKELER, H. (1981). Trends in Structural Semantics. Tübingen: Narr.

FAUCONNIER, G. (1994). Mental Spaces, 2nd. ed. New York: Cambridge University Press.

FILLMORE, C. \& ATKINS, B.T.S. 1994. "Starting where dictionaries stop: the challenge of corpus lexicography”, in Atkins, B.T.S. \& Zampolli, A. (eds.), Computational Approaches to the Lexicon, Oxford: Oxford University Press.

JOHNSON, M. (1987). The Body in the Mind: the Bodily Basis of Meaning, Reason and Imagination. Chicago: Chicago University Press.

LAKOFF, G. (1987). Women, Fire, and Dangerous Things: What Categories Reveal About the Mind. Chicago: University of Chicago Press.

LANGACKER, R. W. (1987). Foundations of Cognitive Grammar, $i$, Theoretical Prerequistites. Standford: Standford University Press.

LANGACKER, R. W. (1990). Concept, Image, and Symbol. The Cognitive Basis of Grammar. Berlin. New York: Mouton de Gruyter.

LEECH, G. (1981). Semantics (2nd. ed.). Harmondsworth, Middlesex: Penguin.

LIPKA, L. (1992). An Outline of English Lexicology (2nd. ed.). Tubingen: Niemeyer.

ROSCH, E. (1978). "Principles of categorization", in Rosch, E. \& Lloyd, B. B. (eds.), Cognition and Categorization, 27-48. Hillsdale. Lawrence Erlbaum.

RUIZ DE MENDOZA IBÁÑEZ, F.J. (1995). "Conceptual schemas and relational domains". Proceedings of the 19th AEDEAN Congress, Vigo, Spain.

RUIZ DE MENDOZA IBÁÑEZ, F.J. (1996). "Semantic networks in conceptual structure". EPOS, 339-356. Madrid: UNED.

TAYLOR, J. R. (1989). Linguistic Categorization. Prototypes in Linguistic Theory. Oxford: Clarendon Press. (2nd. ed. 1995). 